\title{
Spatial and Spatiotemporal Variability of Regional Background Ultrafine Particle Concentrations in the Netherlands
}

\author{
Esther van de Beek, " Jules Kerckhoffs, ${ }^{*}, \|$ Gerard Hoek, Geert Sterk, Kees Meliefste, Ulrike Gehring,
} and Roel Vermeulen

Cite This: Environ. Sci. Technol. 2021, 55, 1067-1075

Read Online

\section{ACCESS I}

Џlll Metrics \& More

Article Recommendations

Supporting Information

ABSTRACT: Studies of the health effects of ultrafine particles (UFPs) in large nationwide cohorts are currently hampered by a lack of knowledge about spatial and spatiotemporal variations in regional background UFPs. We measured the UFP $(10-300 \mathrm{~nm})$ at 20 regional background locations $(3 \times 2$ weeks $)$ across the Netherlands and a reference site continuously over a total period of 14 months in 2016-2017. We compared the overall averages for each site and used kriging to create a regional background spatial map of the Netherlands. Spatiotemporal variability was analyzed by correlating time-series of 2 and $24 \mathrm{~h}$ average concentrations. The overall average measured UFP concentrations at the 20 locations ranged from 3814 to 7070 particles $/ \mathrm{cm}^{3}$. We found the spatial correlation in the UFP concentrations up to $180 \mathrm{~km}$ and clear differences between the north and the more populated southern parts of the country. The average temporal correlation between 2 and $24 \mathrm{~h}$ average UFP concentrations was 0.50 (IQR: 0.36-0.61) and 0.58 (IQR: 0.44-0.75), respectively. Temporal correlation declined weakly with a distance between sites, from 0.58 for sites within $80 \mathrm{~km}$ of each other to 0.47 for sites farther away. The substantial spatial variation in the regional

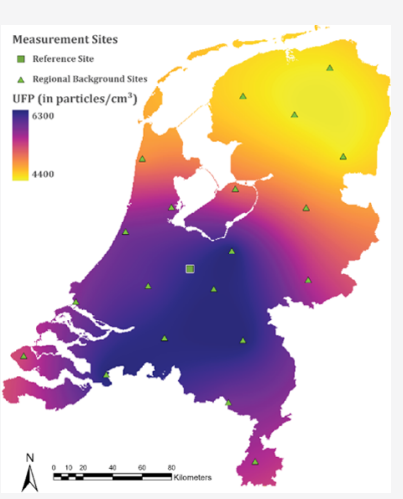
background UFP concentrations suggests that regional variation may contribute importantly to exposure contrast in nationwide health studies of UFP.

\section{INTRODUCTION}

Exposure to ambient air pollutants, such as particulate matter, is associated with adverse health effects. ${ }^{1}$ Ultrafine particles (UFPs; nanoparticles $(<100 \mathrm{~nm})$ ) behave differently than the larger fractions of particulate matter as they can penetrate deeper into the lungs and can enter the bloodstream. ${ }^{2,3}$ However, evidence on the associations between long-term UFP exposure and cardiovascular and inflammatory health effects is still incomplete. ${ }^{4}$ While models have been applied across longer timeframes using short-term UFP monitoring, there is a need for long-term monitoring of UFP and improved deterministic and empirical modeling to gain an understanding of the health effects of long-term UFP exposure. ${ }^{7-9}$ So far, little is known about the spatial and spatiotemporal variability of the UFP concentrations over larger distances.

Most UFP monitoring campaigns for epidemiological studies have been performed in single cities, often with mobile or short-term measurements, ${ }^{10-13}$ or focusing on spatiotemporal variability of UFP in urban environments. ${ }^{7,14-16}$ The focus on urban areas is related to the concept that UFPs are mainly emitted by the traffic and due to coagulation have a much shorter atmospheric lifetime than fine particles. ${ }^{17}$ However, little empirical information is available about the UFP concentrations at regional background locations. Consequently, the health effects of long-term exposure to UFP cannot be readily studied in nationwide cohorts, which have been very powerful in studies of health effects of $\mathrm{PM}_{2.5}$ and $\mathrm{NO}_{2}{ }^{7,18-21}$ A study in California used a chemical transport model at 4 by $4 \mathrm{~km}$ resolution to calculate the background UFP concentration over large areas in California and suggested large variability (IQR: $778-1.747 \mathrm{ng} / \mathrm{m}^{3}$ ) in background concentrations. ${ }^{22}$

The aim of this study is to explore the spatial and spatiotemporal variation of UFP regional background concentrations across the Netherlands. Long-term measurements were conducted three times for 2 weeks on 20 different sites across the country. The first aim of this paper is to assess the spatial variation of the measured and the interpolated average UFP concentrations based on a kriging approach. The second aim is to assess the temporal correlation between the simultaneously measured sites in relation to the distance between sites.

\section{METHODS}

Study Design. We selected 20 regional background sites evenly spread across the Netherlands (Figure 1). For the purpose of this study, we defined regional background sites as

Received: October 9, 2020

Revised: December 17, 2020

Accepted: December 17, 2020

Published: December 30, 2020 


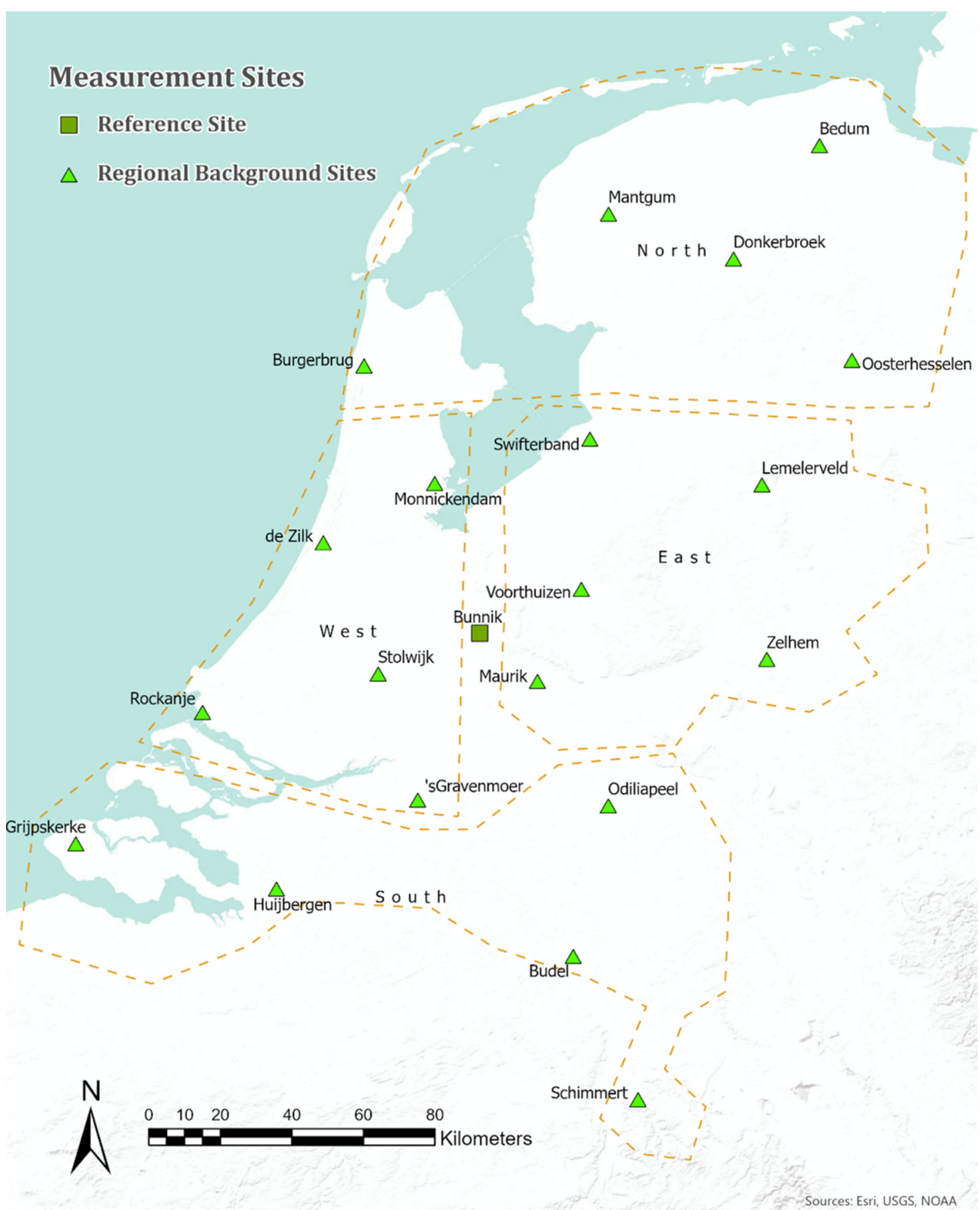

Figure 1. Distribution of the sampling locations in the Netherlands. Bunnik is the reference location (dark green square). Orange dashed line indicates the sites considered as north, east, west, and south.

locations in towns with a maximum of 10000 inhabitants, outside major urban areas. We specifically selected small towns instead of stations outside any settlement (as is common in routine monitoring networks), as our goal was to contribute to human exposure assessment of UFP. Sampling locations were selected to avoid local sources, such as gas stations or parking lots, restaurants, and local industry. Locations also did not have major roads (more than 10000 vehicles/day) within a buffer of $3 \mathrm{~km}$ or were close to ports or airports. Sampling equipment was placed at ground level in gardens of houses, away from the local sources on the microlevel (e.g., extractor hood kitchen), similar to earlier studies. ${ }^{23}$
UFP concentrations were measured (in $1 \mathrm{~s}$ resolution) three times for 2 weeks at each measurement location. Five instruments were available, so four sampling sites and the reference site were measured simultaneously. In each period, we selected one site from each region to limit the temporal variation influences on spatial variation. The set of four sites was equal for all three rounds. Every sampling site was measured during different seasons, totaling 75 measurements (3 times 20 sampling sites and 15 reference site measurements). Because not all 20 sites were measured at the same time, we used the reference site to temporally correct all site 

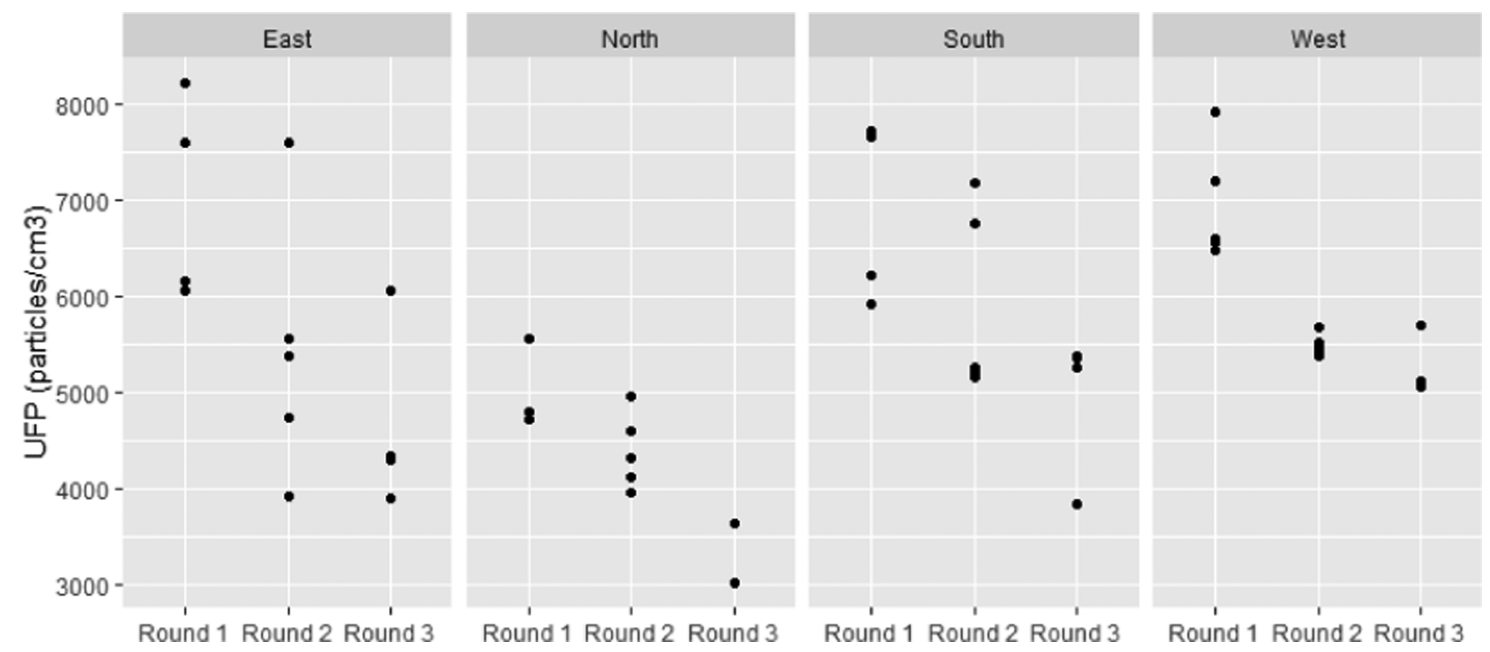

Figure 2. Boxplot of the temporally adjusted UFP concentrations for the three measurement periods by region. Boxes are 25 th to 75 th percentile with black horizontal lines in the boxes referring to the median. The end of the vertical lines indicates 5th and 95th percentiles. Dots represent the individual mean of a measurement site in a single round.

measurements. ${ }^{23}$ All measurements were conducted between June 2016 and November 2017.

The UFP number concentrations were monitored each second with Miniature Diffusion Size Classifiers (MiniDisc). ${ }^{24}$ This device measures particles between 10 and $300 \mathrm{~nm}$. UFPs are generally defined as $<100 \mathrm{~nm}$, but the major part of the total particle count is in the $10-100 \mathrm{~nm}$ range. ${ }^{8,14,17}$ Therefore, we use UFPs to refer to our total particle count number measurements. We did not include a comparison with other measurement devices in this study, but the monitors were compared with Condensation Particles Counters (CPCs) in a study by van Nunen et al. 2017 using the same instruments as in our study. The ratio between the devices was found to be 1.0 .

Data Cleaning. Measurements were removed when (1) there were error messages from the instrument (low flow, voltage); (2) the ratio between the UFP concentration and the UFP concentration of the subsequent second was above 10 or below 0.1 (with subsequent unrealistic data removed as well) $;^{16}$ or (3) the count was lower than 500 particles $/ \mathrm{cm}^{3}$ (indicating unrealistic values). Individual $1 \mathrm{~s}$ measurements were removed in less than $0.1 \%$ of all cases. Two hour average, $24 \mathrm{~h}$ average, and an overall mean concentration were then calculated for all sites and used for further analysis. When less than $75 \%$ of the data of a site were available (because of the defective power supply), we did not calculate an overall mean concentration for that site. Because UFP concentrations were slightly skewed, we log-transformed all averages for sensitivity analysis. From a health point of view, all results in the main paper are based on nontransformed data.

Data Correction. We corrected for differences between the devices by co-locating them in a laboratory setting and corrected temporal differences for the spatial analyses using a reference site. These procedures are more elaborately described in the Supporting Information (Supplement A). In brief, differences between the devices were assessed by colocating all five devices for 1-2 days before and after every two-week measurement. We corrected each measurement campaign based on the calculated median ratios between the reference device and other devices of each co-located comparison. All individual ratios are shown in the Supporting
Information Table A.1, with average medians ranging from 0.99 to 1.19 .

To correct for temporal variation in the spatial analyses, we used a single reference site in the middle of the country with the same equipment as all other sites (Figure 1). The reference site had the same data correction procedure and restrictions as the sampling locations regarding potential local sources. A correction was performed using the difference method. ${ }^{25}$ The overall average of the reference site is subtracted from the average of each of the 15 measurement periods at the reference site. This difference is then added to the measurements of the corresponding period at the sampling locations.

Spatial Variability. To assess the spatial variability of UFP concentrations, we performed a geostatistical space-time procedure and kriging interpolation. ${ }^{26}$ In brief, this method assumes that the spatial correlation for all measurements combined equals the spatial correlation structure for all three measurement periods separately. The three measurements at the same sampling locations are treated as independent temporal replicates. This procedure is an adoption of a methodology that has previously been used to spatially model the wind-blown mass transport based on a limited number of point measurements. ${ }^{26} \mathrm{~A}$ full description of the space-time procedure and kriging approach (including semivariogram) can be found in the Supporting Information (Supplement B).

Spatiotemporal Correlation. We used $2 \mathrm{~h}$ (within-day variation) and $24 \mathrm{~h}$ (day-to-day variation) moving averages for the spatiotemporal analysis. Correlations between all sampling locations (including the reference site) were examined by calculating Pearson, Spearman, and cross-correlations. Crosscorrelation refers to the correlation between concentrations with different lagged time periods. For example, the concentration at a certain site is correlated with the concentration at another site a number of hours earlier or later. In our study, we assessed the maximum cross-correlation with lags up to $3 \mathrm{~h}$ in both directions. We also assessed the influence of distance on the temporal correlation between two sampling sites.

We further checked the efficacy of the difference method to adjust for temporal variation using one reference site for the entire country. First, we applied the difference method to each 2 and $24 \mathrm{~h}$ averaged data point in the time-series. Next, we 


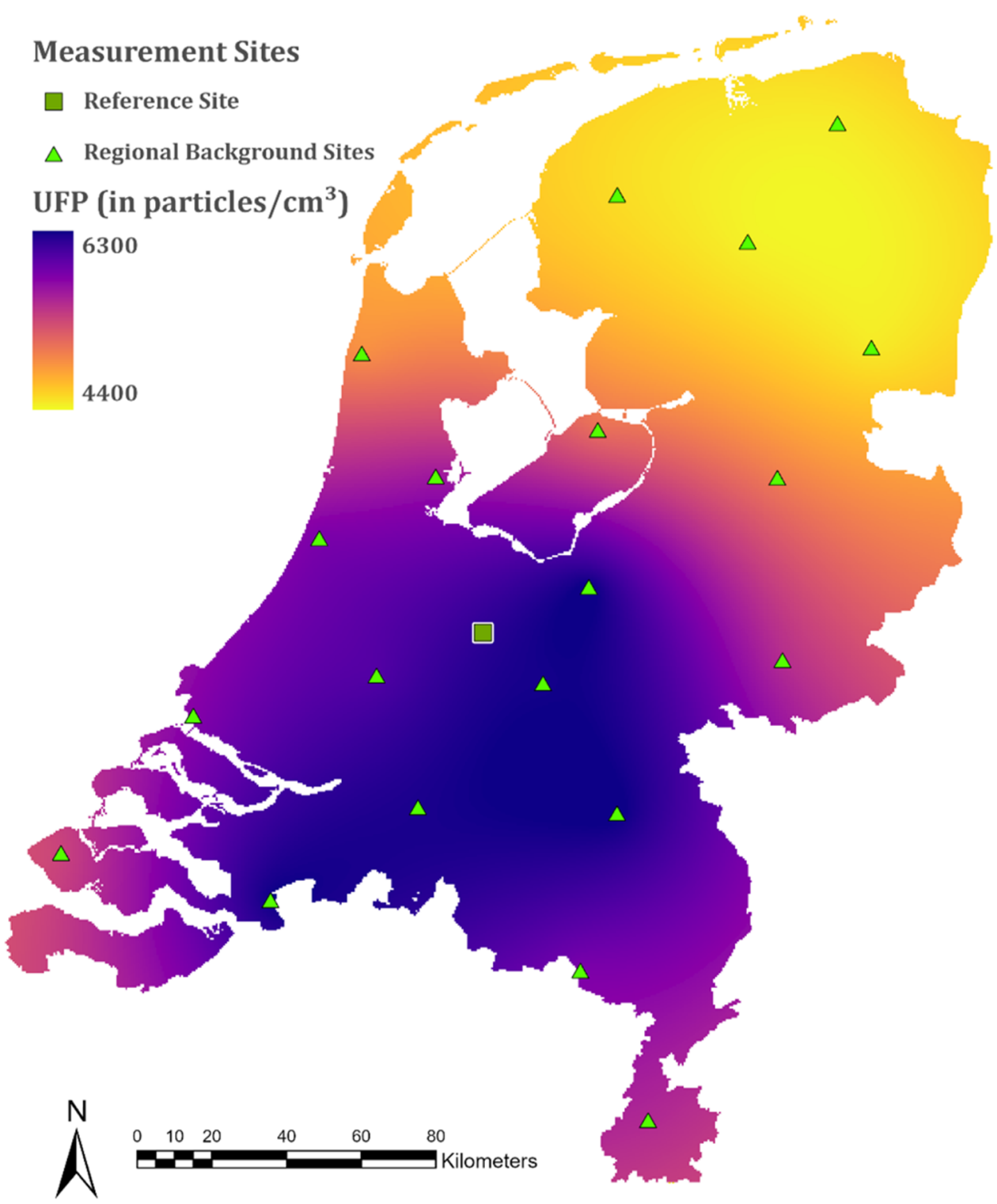

Figure 3. Map of average UFP regional background concentrations in the Netherlands.

compared the variance in the temporally corrected time-series and the variance of the unadjusted time-series using the formula: 1 - variance (adjusted)/variance (unadjusted) to calculate the proportion of variance explained (PVE). This means that a PVE between 0 and 1 relates to a decrease in variance. A PVE value below 0 means that the variance increased after using the difference method.

\section{RESULTS}

Figure 2 shows the distribution of the concentrations per period of measurements. Missing data due to equipment failure occurred for 10 out of 75 measurements (13\%). For one reference measurement, only $20 \%$ of the data was available. We decided to exclude this reference measurement and the measurements at the sampling locations of the same period. This resulted in 10 sampling locations with all three measurements available, 9 sampling sites with 2 measurements, and one location with one measurement (Supplement A). All individual 2-week average concentrations per site are shown in Figure 2 and Supplement A. Temporally corrected biweekly UFP concentrations ranged from 3028 to 8202 particles $/ \mathrm{cm}^{3}$.
Concentrations were generally higher in the first round of measurements and were consistently lower in the north of the country compared to other regions of the Netherlands. Round 1 was mostly in the fall of 2016, round 2 in winter 2016-2017, and round 3 in the summer and fall of 2017. The measured average concentrations over the three periods ranged from 3814 to 7080 particles $/ \mathrm{cm}^{3}$. The UFP mean and median (less affected by high values) were highly correlated, documenting that outliers did not affect the pattern of 14 day average concentrations.

Spatial Variability. The regional differences are shown in Figure 3. A spherical model was fitted through the computed standardized semivariogram values (Figure B.1). The fitted spherical model has a range of $180.9 \mathrm{~km}$, which indicates the presence of spatial correlation up to $181 \mathrm{~km}$. The nugget (the value that the semivariogram model attains at lag $=0$ : intercept) and sill (the value that the semivariogram model attains at the range) values are, respectively, 0.193 and 0.582 . All interpolated maps (Figure B.2, i.e., maps per measurement period and the average map) showed that the kriging resulted in a moderate loss of the variation compared to the measured 

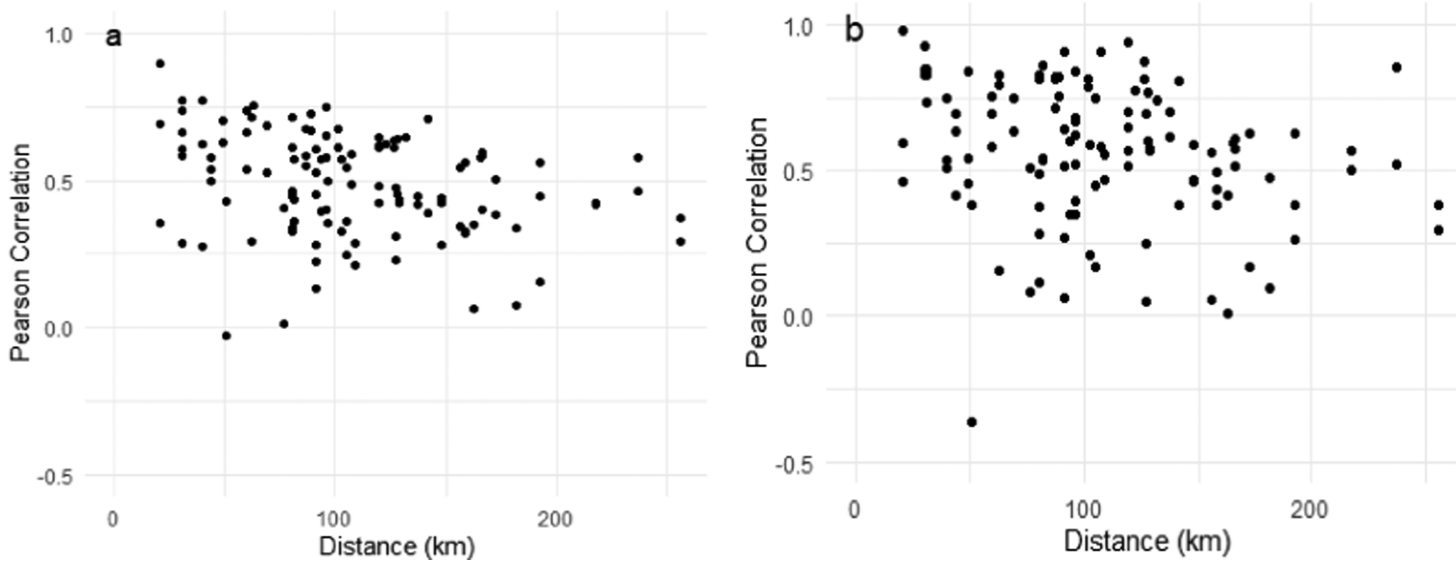

Figure 4. Scatterplot of the Pearson correlation versus distance. Pearson correlation calculated based on 2 h (a) and 24 h (b) average UFP concentrations at two simultaneously measured sampling sites, per sampling round of 2 weeks.
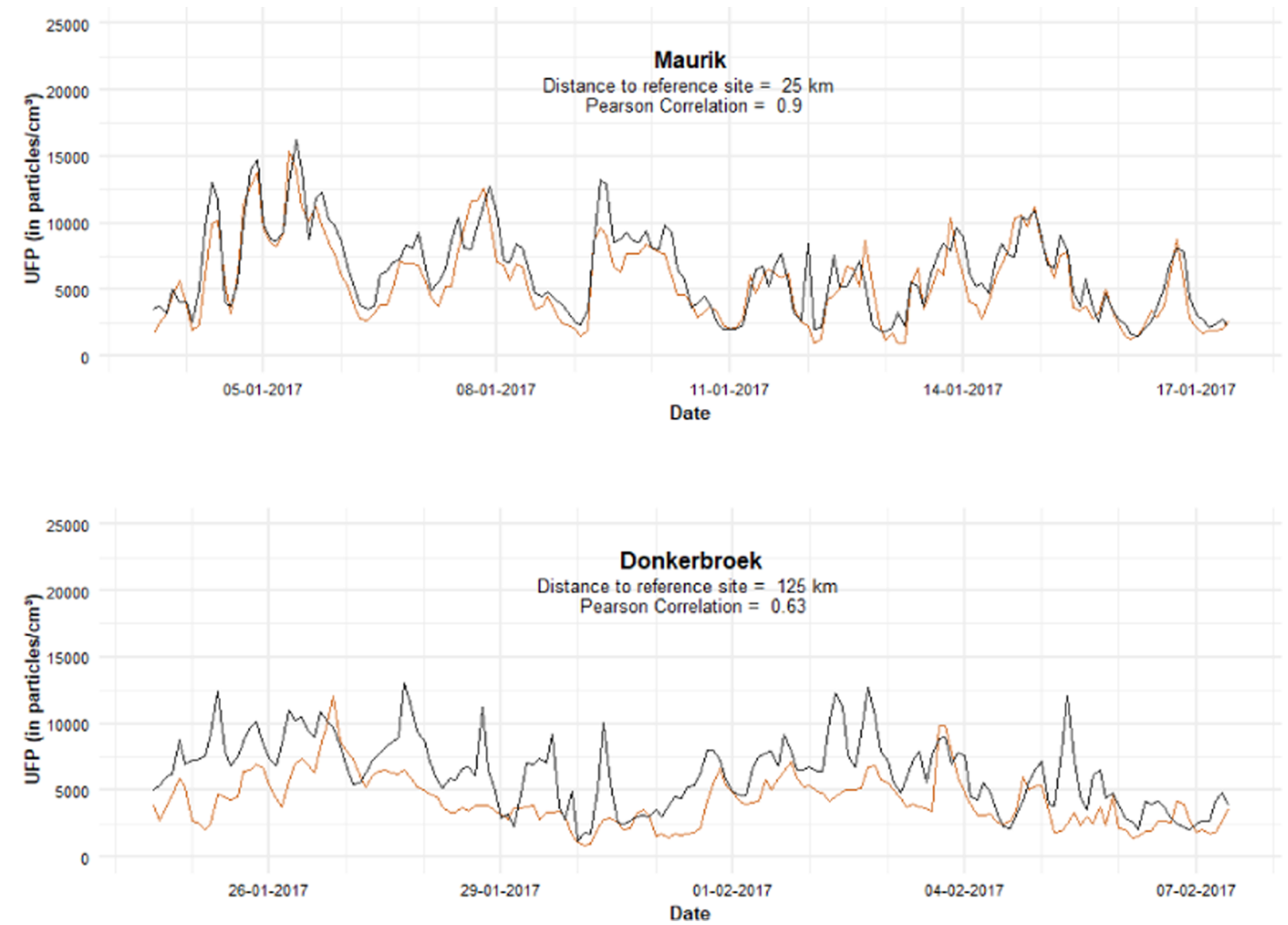

Figure 5. Temporal variation of 2 hourly averaged UFP concentrations (particles $/ \mathrm{cm}^{3}$ ) at the reference site (black) and the sampling locations (brown) Maurik and Donkerbroek for one round.

variations. The predicted concentrations in the average kriging map range from 4.414 to 6.221 particles $/ \mathrm{cm}^{3}$, whereas the overall measured average concentrations in the three periods range from 3.814 to 7.080 particles $/ \mathrm{cm}^{3}$. The error maps of the individual kriging interpolations (Figure B.2) and leave-oneout-cross-validation (LOOCV) (Figures B.3-B.5) show that the uncertainty of the prediction increases as the distance from the observation locations increases and uncertainty is greater toward the edges of the map.
Spatiotemporal Correlations. Figure 4 shows the correlation between all simultaneously measured sampling sites, with all $1 \mathrm{~s}$ measurements averaged over $2 \mathrm{~h}$ (Figure $4 \mathrm{a}$ ) and with all measurements averaged over $24 \mathrm{~h}$ (Figure $4 \mathrm{~b}$ ). The median correlations are 0.50 between $2 \mathrm{~h}$ average concentrations at the simultaneously measured sites and 0.58 between the $24 \mathrm{~h}$ average measurements. Large variability in pairwise correlations is observed. The interquartile range for 2 $\mathrm{h}$ averages was $0.36-0.61$ and $0.44-0.75$ for $24 \mathrm{~h}$ averages. We found one site (Round 1 in "De Zilk") with a negative 
correlation to the reference site in our data (both for $2 \mathrm{~h}$ and especially $24 \mathrm{~h}$ average). Especially, in the first week of the measurement, there seem to be local influences that we cannot account for (Figure C.1). The average diurnal variation followed the same pattern at all sites including the reference site (Figure C.3). This indicates that the measurements were not systematically impacted by local sources. Inspection of individual hourly average plots per study period per location generally gave no indication of incidental local sources, except for the first measurement round in one site (Figure C1). The correlations for log-transformed PNC were slightly higher than that for nontransformed one (Table C2).

For all $2 \mathrm{~h}$ average concentrations, we also show time-series plots in the Supporting Information (Figure C.1), with two examples shown in Figure 5. These plots show that the UFP concentrations behave similarly in time and magnitude for both the sampling location and reference site, independent of the actual concentrations of both sites. This can also be observed by the average diurnal pattern of each measurement site (Figure C.2). Figure 5 shows time-series graphs of a sampling location close to the reference site (Maurik, $25 \mathrm{~km}$, in the west of the country) and one further away (Donkerbroek, $125 \mathrm{~km}$ in the north of the country). The variation in the concentrations of Maurik and the reference site is very similar, both in behavior at the base level (coarse variation across days), magnitude, and short-term variation (within-day variation). The measurement at Donkerbroek still shows similar behavior at the base level as the reference site but not regarding the short-term variation. Furthermore, the timeseries plot also demonstrates a considerable, although the consistent difference in the magnitude of approximately 4000 particles $/ \mathrm{cm}^{3}$ when comparing Donkerbroek to the reference location. This is also reflected in the difference between the overall means of this period of Donkerbroek and the reference site.

The correlations and cross-correlations calculated in addition to the time-series graphs corroborate these findings. Table C.1 shows the (cross-)correlations and corresponding time lags. The median maximum cross-correlation was slightly higher than the Pearson correlation: 0.54 (95\% confidence interval $0.47-0.57)$. Time lags for the maximum crosscorrelation exceeded $2 \mathrm{~h}$ only on two occasions. Crosscorrelations within sampling locations are quite consistent (Table C.1).

After correcting for temporal variation with the difference method, the variation decreased for 31 (63\%) of the measurements (Table C.1), with an overall average of $8 \%$. Variation decreased in 41 sites (84\%) when only day-to-day $(24 \mathrm{~h})$ variation was assessed, with an overall average of $18 \%$.

Table 1 shows the relationship between distance and correlation between the simultaneously measured sites. Measurement sites were grouped based on the distance

Table 1. Influence of Distance between Sites on Spatiotemporal Correlation

$\begin{array}{cccccc}\text { distance } & \begin{array}{c}\text { median } \\ \text { Pearson } \\ \text { between } \\ \text { correlation }\end{array} & \begin{array}{c}\text { median } \\ \text { cross- } \\ \text { correlation } \\ 2 \mathrm{~h}\end{array} & \begin{array}{c}\text { median } \\ \text { cross- } \\ \text { correlation } \\ 2 \mathrm{~km})\end{array} & \begin{array}{c}\text { median } \\ \text { PVE }\end{array} & \begin{array}{c}\text { median } \\ \text { PVE }\end{array} \\ <50 & 0.58 & 0.58 & 0.50 & 0.30 & 0.24 \\ 50-80 & 0.57 & 0.58 & 0.55 & 0.15 & 0.24 \\ >80 & 0.44 & 0.47 & 0.43 & 0.23 & 0.05\end{array}$

between sites in such a way that each group contained nearly an equal number of pairs. For sites that are within $50 \mathrm{~km}$ of each other, the median Pearson correlation is 0.58, whereas the median correlation between sites more than $80 \mathrm{~km}$ apart decreased to 0.44 . Also, the proportion of explained variance is higher for sites that are close to the reference site, especially when day-to-day variance (PVE $24 \mathrm{~h}$ ) is used (Table 1). Median Pearson correlation values increased when the data was log-transformed. Pearson correlation scores were 0.69 $(>50 \mathrm{~km}), 0.61(50-80 \mathrm{~km})$, and $0.55(>80 \mathrm{~km})$, see also Table C.2.

\section{DISCUSSION}

This paper describes the spatial and spatiotemporal variability of the regional background UFP concentrations in the Netherlands. We found substantial spatial differences between the regional background UFP concentrations, especially between the north and the more populated southern parts of the Netherlands. We found a moderate temporal correlation between the UFP concentrations at simultaneously measured sampling locations, which varied by distance.

Spatial Variability. We designed a long-term UFP measurements campaign because routine monitoring, nationwide chemical transport modeling (CTM), and satellite observations of UFPs are not available in the Netherlands and in most countries. We then used a pooled kriging approach to assess spatial variation in this study because of the limited number of sites. While relatively old, kriging can still be considered state-of-the-art modeling in settings with smoothly changing concentration patterns and limited local sources. Alternative methods, such as the LUR methods are not well suited to describe large-scale concentration patterns related to, e.g., coagulation of ultrafine particles or new particle formation, especially when the number of sites drops below $20 .^{27,28}$ Moreover, the LUR models are limited to represent differences in the background concentrations well for scales larger than about $10 \mathrm{~km}$. 29,30

Regional background UFP concentrations differed across the Netherlands, with higher concentrations in the more urbanized southern parts of the Netherlands and lower concentrations in the north. This north-south difference is consistent with the measured and modeled concentrations of other combustion source-related air pollutants (such as soot, $\mathrm{PM}_{2.5}$, and $\mathrm{NO}_{2}$ ) in the Netherlands. ${ }^{7,31}$ The lower concentration in the north of the country has been attributed to a combination of the lower regional emissions from traffic, households, and industry and larger distance to major foreign sources areas in Germany and Belgium particularly. ${ }^{23}$ Relative differences (maximum/minimum) in that study were 1.5 for $\mathrm{PM}_{2.5}$ and 2.2 for $\mathrm{NO}_{2}$, respectively. In our study, we found a ratio of 1.9.

Interpretation of the spatial variation of UFPs has mostly focused on the urban and local (roadside) scale. ${ }^{17}$ Relatively little is known about the sources and the factors at the regional scale. Compared to fine particles, UFPs are expected to travel over shorter distances due to their short atmospheric lifetime. ${ }^{32,33}$ While our monitoring sites were located away from major roads and small local sources, there is increasing evidence that large source areas do affect the UFP concentrations at distances of several tens of kilometers. ${ }^{34-36}$ Several studies have now documented contributions of major airports to UFP concentrations at least $10 \mathrm{~km}$ away from the airport. $^{34-37}$ In the Netherlands, measurable UFP contributions of a major airport and a large industrial area including 
refineries were found at a regional background site up to $40 \mathrm{~km}$ away from the source area. ${ }^{34,35}$ Ultrafine particles may travel relatively large distances because the relatively slow coagulation processes in the diluted plumes or new particles may be formed from gaseous precursors. Our measurements may further be affected by residential sources including domestic heating, which in the Netherlands is primarily based upon natural gas. Wood burning is an increasing residential source as well. Regional nucleation events can have a large impact on UFP concentrations. ${ }^{17}$ Because the Netherlands is a flat and small country, it can be considered as one airshed. Regional nucleation events therefore would contribute to smooth spatial patterns. Background concentrations of UFPs are mainly driven by wind speed, precipitation, temperature, and relative humidity. ${ }^{38}$ These weather factors do not differ much across the country.

Understanding the regional differences in the UFP concentrations is of great importance. While most people live in urban areas, it is not feasible to measure in every city or town in a country. Our measurements suggest that cities equal in local and urban sources but are located in different regions of the country experience different concentrations due to variation in the regional background concentration. On top of that, the regional differences we found in this study are often in the same order of magnitude as the predicted differences between the streets within a city. For example, the measured annual average UFP concentrations in the city of Augsburg, Germany, ranged from 7000 to 13000 particles $/ \mathrm{cm}^{3}$, ${ }^{12}$ and predictor variables in a previously developed UFP model in the Netherlands were able to distinguish differences of up to 5000 particles $/ \mathrm{cm}^{3}$ between the 90th and 10th percentile for each predictor. $^{11}$ Klompmaker et al. ${ }^{25}$ measured the short-term concentrations in two Dutch cities and found an average difference of 5601 particles $/ \mathrm{cm}^{3}$ between traffic (15.464 particles $/ \mathrm{cm}^{3}$ ) and urban background sites (9.863 particles/ $\mathrm{cm}^{3}$ ). Regional background differences up to 3000 particles/ $\mathrm{cm}^{3}$ are therefore important to consider in health studies covering populations in a large geographic area. Regional background variation may contribute significantly to the overall variability in exposure in a nationwide health study. We specifically used the kriging map of this study to represent the regional background component in a national land-use regression model. The national LUR is now further derived from mobile monitoring data and local and urban source predictors. ${ }^{39}$ The importance of the regional background data is therefore mostly in distinguishing the UFP exposure in towns and cities in different parts of the country.

Spatiotemporal Correlation. The median cross-correlation of 0.54 indicates a moderate temporal relationship between the sampling sites and the reference location. Hofman et al. ${ }^{14}$ compared the long-term UFP measurements in four different European cities and found similar patterns. The highest correlation they found was between London and Leicester $(143 \mathrm{~km}$, Spearman correlation $=0.50)$. Such moderate correlations support the use of a reference site to correct for the temporal variation over distances of up $200 \mathrm{~km}$ (like the Netherlands) but suggest that this adjustment is of limited value, as supported by our variance reduction analysis. Therefore, sampling designs to minimize bias due to temporal variation in assessing the spatial variation are needed. Studies analyzing acute health effects of UFP exposure, like time-series studies, are still restricted to measurement stations that are close to all participants.
Most studies that sample air pollution concentrations at different locations at various time points use a central reference site to adjust for temporal variation. The range of the variogram of $181 \mathrm{~km}$ indicates the presence of spatial autocorrelation up to about $200 \mathrm{~km}$. The maximum distance between the sampling sites and the reference location in this study was $165 \mathrm{~km}$. We did find higher correlations for sampling locations close to the reference site but found only a small decrease in the correlation with increasing distance. Furthermore, the difference method for the correction of temporal variation decreased the variation in the time-series of the sampling location in only $63 \%$ of the cases.

The time lags of the maximum cross-correlations between concentrations at a sampling location and the reference site were $2 \mathrm{~h}$ or smaller in almost all cases. This supports our averaging period of $2 \mathrm{~h}$ for all temporal analyses. Correlations with (cross-correlation) and without (Pearson) lags were therefore similar. Not many studies explore time lags between time-series of air pollution concentrations between sampling sites. A study in China, examining the $\mathrm{PM}_{2.5}$ concentration time-series lags between Beijing and Zhangjiakou, reported time lags of $6-50 \mathrm{~h}$ between the two cities, approximately 200 $\mathrm{km}$ apart. ${ }^{40} \mathrm{~A}$ lag of 1 or $2 \mathrm{~h}$ between sites that are more than $100 \mathrm{~km}$ apart based on the transport between the two locations seems unlikely because this would require a constant wind speed of $50-100 \mathrm{~km} / \mathrm{h}$, whereas the average wind speed in the Netherlands is $8 \mathrm{~km} / \mathrm{h}$.

Strengths and Limitations. In this study, we were able to measure the regional background UFP across a wide geographic area over a larger period of time. So far, most UFP measurement campaigns have been conducted within cities as local UFP sources are concentrated in major cities and monitoring is costly and labor-intensive. The sample size of this study (20 sampling locations) was still rather small to produce nationwide maps. Yet, with our kriging approach, we were able to make interpolations with limited prediction errors despite the small number of locations and measurements. The distribution of the predicted concentrations throughout the country was consistent for all three measurement periods (Figure B.2). This indicates that the interpolated map gives us a reasonably accurate general description of the spatial variability of regional background UFP concentration in the Netherlands, although we cannot exclude that we have missed specific regional patterns due to the limited number of sites. A higher density of the monitoring network would increase the accuracy of the prediction.

The method of producing a pooled variogram assumes independence between the three measurement periods. However, the repeated measurements of concentrations at a specific sampling site are likely (temporally) correlated between periods because we expect the emission sources that influence the difference between various sampling locations to be largely consistent over time. We consider the temporal independence between measurements at the same sites to be large enough to justify the use of a pooled variogram because the measurements were far apart enough in time. On average, measurements at the same site were 165 days apart. Our study was primarily empirical and not designed to elucidate the physicochemical processes explaining the factors contributing to the spatial and temporal variation. 


\section{ASSOCIATED CONTENT}

\section{(s) Supporting Information}

The Supporting Information is available free of charge at https://pubs.acs.org/doi/10.1021/acs.est.0c06806.

Data correction procedures (Supplement A), elaborate explanation of pooled kriging approach with spatial variation of UFP over the different rounds (Supplement B), spatiotemporal correlation statistics, and all timeseries figures (Supplement C) (PDF)

\section{AUTHOR INFORMATION}

\section{Corresponding Author}

Jules Kerckhoffs - Institute for Risk Assessment Sciences (IRAS), Division of Environmental Epidemiology, Utrecht University, 3584 CK Utrecht, The Netherlands; ๑ orcid.org/0000-0001-9065-6916; Email: j.kerckhoffs@ uu.nl

\section{Authors}

Esther van de Beek - Institute for Risk Assessment Sciences (IRAS), Division of Environmental Epidemiology, Utrecht University, 3584 CK Utrecht, The Netherlands

Gerard Hoek - Institute for Risk Assessment Sciences (IRAS), Division of Environmental Epidemiology, Utrecht University, 3584 CK Utrecht, The Netherlands

Geert Sterk - Department of Physical Geography, Utrecht University, 3508 TC Utrecht, The Netherlands

Kees Meliefste - Institute for Risk Assessment Sciences (IRAS), Division of Environmental Epidemiology, Utrecht University, 3584 CK Utrecht, The Netherlands

Ulrike Gehring - Institute for Risk Assessment Sciences (IRAS), Division of Environmental Epidemiology, Utrecht University, 3584 CK Utrecht, The Netherlands

Roel Vermeulen - Institute for Risk Assessment Sciences (IRAS), Division of Environmental Epidemiology, Utrecht University, 3584 CK Utrecht, The Netherlands; Julius Center for Health Sciences and Primary Care, University Medical Center, University of Utrecht, 3584 CK Utrecht, The Netherlands

Complete contact information is available at: https://pubs.acs.org/10.1021/acs.est.0c06806

\section{Author Contributions}

"E.v.d.B. and J.K. contributed equally to this work.

\section{Notes}

The authors declare no competing financial interest.

\section{REFERENCES}

(1) HEITraffic-Related Air Pollution: A Critical Review of the Literature on Emissions, Exposure, and Health Effects; HEI, 2010; Special Re (January), pp 1-386.

(2) Oberdörster, G.; Oberdörster, E.; Oberdörster, J. Nanotoxicology: An Emerging Discipline Evolving from Studies of Ultrafine Particles. Environ. Health Perspect. 2005, 113, 823-839.

(3) Peters, A.; Veronesi, B.; Calderón-Garcidueñas, L.; Gehr, P.; Chen, L.; Geiser, M.; Reed, W.; Rothen-Rutishauser, B.; Schürch, S.; Schulz, H. Translocation and Potential Neurological Effects of Fine and Ultrafine Particles a Critical Update. Part. Fibre Toxicol. 2006, 3, 13.

(4) Ohlwein, S.; Kappeler, R.; Kutlar Joss, M.; Künzli, N.; Hoffmann, B. Health Effects of Ultrafine Particles: A Systematic Literature Review Update of Epidemiological Evidence. Int. J. Public Health 2019, 547-559.
(5) Montagne, D. R.; Hoek, G.; Klompmaker, J. O.; Wang, M.; Meliefste, K.; Brunekreef, B. Land Use Regression Models for Ultrafine Particles and Black Carbon Based on Short-Term Monitoring Predict Past Spatial Variation. Environ. Sci. Technol. 2015, 49, 8712-8720.

(6) Jones, R. R.; Hoek, G.; Fisher, J. A.; Hasheminassab, S.; Wang, D.; Ward, M. H.; Sioutas, C.; Vermeulen, R.; Silverman, D. T. Land Use Regression Models for Ultrafine Particles, Fine Particles, and Black Carbon in Southern California. Sci. Total Environ. 2020, 699, No. 134234.

(7) Eeftens, M.; Phuleria, H. C.; Meier, R.; Aguilera, I.; Corradi, E.; Davey, M.; Ducret-Stich, R.; Fierz, M.; Gehrig, R.; Ineichen, A.; Keidel, D.; Probst-Hensch, N.; Ragettli, M. S.; Schindler, C.; Künzli, N.; Tsai, M. Y. Spatial and Temporal Variability of Ultrafine Particles, $\mathrm{NO}<$ inf $>2</$ Inf $>, \mathrm{PM}<$ inf $>2.5</$ Inf $>, \mathrm{PM}<$ inf $>2.5</$ Inf $>$ Absorbance, $\mathrm{PM}<\mathrm{inf}>10</ \mathrm{Inf}>$ and $\mathrm{PM}<\mathrm{inf}>$ coarse $</ \mathrm{Inf}>$ in Swiss Study Areas. Atmos. Environ. 2015, 111, 60-70.

(8) Hennig, F.; Quass, U.; Hellack, B.; Küpper, M.; Kuhlbusch, T. A. J.; Stafoggia, M.; Hoffmann, B. Ultrafine and Fine Particle Number and Surface Area Concentrations and Daily Cause-Specific Mortality in the Ruhr Area, Germany, 2009-2014. Environ. Health Perspect. 2018, 126, No. 027008.

(9) Downward, G. S.; van Nunen, E. J. H. M.; Kerckhoffs, J.; Vineis, P.; Brunekreef, B.; Boer, J. M. A.; Messier, K. P.; Roy, A.; Verschuren, W. M. M.; van Der Schouw, Y. T.; Sluijs, I.; Gulliver, J.; Hoek, G.; Vermeulen, R. Long-Term Exposure to Ultrafine Particles and Incidence of Cardiovascular and Cerebrovascular Disease in a Prospective Study of a Dutch Cohort. Environ. Health Perspect. 2018, 126, No. 127007.

(10) Hatzopoulou, M.; Valois, M. F.; Levy, I.; Mihele, C.; Lu, G.; Bagg, S.; Minet, L.; Brook, J. Robustness of Land-Use Regression Models Developed from Mobile Air Pollutant Measurements. Environ. Sci. Technol. 2017, 51, 3938-3947.

(11) Kerckhoffs, J.; Hoek, G.; Vlaanderen, J.; van Nunen, E.; Messier, K.; Brunekreef, B.; Gulliver, J.; Vermeulen, R. Robustness of Intra Urban Land-Use Regression Models for Ultrafine Particles and Black Carbon Based on Mobile Monitoring. Environ. Res. 2017, 159, 500-508.

(12) Wolf, K.; Cyrys, J.; Harciníková, T.; Gu, J.; Kusch, T.; Hampel, R.; Schneider, A.; Peters, A. Land Use Regression Modeling of Ultrafine Particles, Ozone, Nitrogen Oxides and Markers of Particulate Matter Pollution in Augsburg, Germany. Sci. Total Environ. 2017, 1531-1540.

(13) Patton, A. P.; Collins, C.; Naumova, E. N.; Zamore, W.; Brugge, D.; Durant, J. L. An Hourly Regression Model for Ultrafine Particles in a Near-Highway Urban Area. Environ. Sci. Technol. 2014, $48,3272-3280$.

(14) Hofman, J.; Staelens, J.; Cordell, R.; Stroobants, C.; Zikova, N.; Hama, S. M. L.; Wyche, K. P.; Kos, G. P. A.; Van Der Zee, S.; Smallbone, K. L.; Weijers, E. P.; Monks, P. S.; Roekens, E. Ultrafine Particles in Four European Urban Environments: Results from a New Continuous Long-Term Monitoring Network. Atmos. Environ. 2016, $136,68-81$.

(15) Von Bismarck-Osten, C.; Birmili, W.; Ketzel, M.; Massling, A.; Petäjä, T.; Weber, S. Characterization of Parameters Influencing the Spatio-Temporal Variability of Urban Particle Number Size Distributions in Four European Cities. Atmos. Environ. 2013, 77, 415-429.

(16) Puustinen, A.; Hämeri, K.; Pekkanen, J.; Kulmala, M.; de Hartog, J.; Meliefste, K.; ten Brink, H.; Kos, G.; Katsouyanni, K.; Karakatsani, A.; Kotronarou, A.; Kavouras, I.; Meddings, C.; Thomas, S.; Harrison, R.; Ayres, J. G.; van der Zee, S.; Hoek, G. Spatial Variation of Particle Number and Mass over Four European Cities. Atmos. Environ. 2007, 41, 6622-6636.

(17) HEI Review Panel. Understanding the Health Effects of Ambient Ultrafine Particles. Health Eff. Inst. 2013, 122.

(18) Milanzi, E. B.; Koppelman, G. H.; Smit, H. A.; Wijga, A. H.; Oldenwening, M.; Vonk, J. M.; Brunekreef, B.; Gehring, U. Air 
Pollution Exposure and Lung Function until Age 16 Years: The PIAMA Birth Cohort Study. Eur. Respir. J. 2018, 52, No. 1800218.

(19) Pope, C. A.; Burnett, R. T.; Thun, M. J.; Calle, E. E.; Krewski, D.; Ito, K.; Thurston, G. D. Lung Cancer, Cardiopulmonary Mortality, and Long-Term Exposure to Fine Particulate Air Pollution. J. Am. Med. Assoc. 2002, 287, 1132-1141.

(20) Fischer, P. H.; Marra, M.; Ameling, C. B.; Hoek, G.; Beelen, R.; de Hoogh, K.; Breugelmans, O.; Kruize, H.; Janssen, N. A. H.; Houthuijs, D. Air Pollution and Mortality in Seven Million Adults: The Dutch Environmental Longitudinal Study (DUELS). Environ. Health Perspect. 2015, 123, 697-704.

(21) Beelen, R.; Raaschou-Nielsen, O.; Stafoggia, M.; Andersen, Z. J.; Weinmayr, G.; Hoffmann, B.; Wolf, K.; Samoli, E.; Fischer, P.; Nieuwenhuijsen, M.; Vineis, P.; Xun, W. W.; Hoek, G. Effects of Long-Term Exposure to Air Pollution on Natural-Cause Mortality: An Analysis of 22 European Cohorts within the Multicentre ESCAPE Project. Lancet 2014, 383, 785-795.

(22) Ostro, B.; Hu, J.; Goldberg, D.; Reynolds, P.; Hertz, A.; Bernstein, L.; Kleeman, M. J. Associations of Mortality with LongTerm Exposures to Fine and Ultrafine Particles, Species and Sources: Results from the California Teachers Study Cohort. Environ. Health Perspect. 2015, 123, 549-556.

(23) Eeftens, M.; Tsai, M. Y.; Ampe, C.; Anwander, B.; Beelen, R.; Bellander, T.; Cesaroni, G.; Cirach, M.; Cyrys, J.; de Hoogh, K.; De Nazelle, A.; de Vocht, F.; Declercq, C.; Dedele, A.; Eriksen, K.; Galassi, C.; Gražulevičiene, R.; Grivas, G.; Heinrich, J.; Hoffmann, B.; Iakovides, M.; Ineichen, A.; Katsouyanni, K.; Korek, M.; Krämer, U.; Kuhlbusch, T.; Lanki, T.; Madsen, C.; Meliefste, K.; Mölter, A.; Mosler, G.; Nieuwenhuijsen, M.; Oldenwening, M.; Pennanen, A.; Probst-Hensch, N.; Quass, U.; Raaschou-Nielsen, O.; Ranzi, A.; Stephanou, E.; Sugiri, D.; Udvardy, O.; Vaskövi, E.; Weinmayr, G.; Brunekreef, B.; Hoek, G. Spatial Variation of PM2.5, PM10, PM2.5 Absorbance and PMcoarse Concentrations between and within 20 European Study Areas and the Relationship with NO2 - Results of the ESCAPE Project. Atmos. Environ. 2012, 62, 303-317.

(24) Fierz, M.; Houle, C.; Steigmeier, P.; Burtscher, H. Design, Calibration, and Field Performance of a Miniature Diffusion Size Classifier. Aerosol Sci. Technol. 2011, 45, 1-10.

(25) Klompmaker, J. O.; Montagne, D. R.; Meliefste, K.; Hoek, G.; Brunekreef, B. Spatial Variation of Ultrafine Particles and Black Carbon in Two Cities: Results from a Short-Term Measurement Campaign. Sci. Total Environ. 2015, 508, 266-275.

(26) Sterk, G.; Stein, A. Mapping Wind-Blown Mass Transport by Modeling Variability in Space and Time. Soil Sci. Soc. Am. J. 1997, 61, 232.

(27) Basagaña, X.; Rivera, M.; Aguilera, I.; Agis, D.; Bouso, L.; Elosua, R.; Foraster, M.; de Nazelle, A.; Nieuwenhuijsen, M.; Vila, J.; Künzli, N. Effect of the Number of Measurement Sites on Land Use Regression Models in Estimating Local Air Pollution. Atmos. Environ. 2012, 54, 634-642.

(28) Wang, M.; Beelen, R.; Basagana, X.; Becker, T.; Cesaroni, G.; De Hoogh, K.; Dedele, A.; Declercq, C.; Dimakopoulou, K.; Eeftens, M.; Forastiere, F.; Galassi, C.; Gražulevičiene, R.; Hoffmann, B.; Heinrich, J.; Iakovides, M.; Künzli, N.; Korek, M.; Lindley, S.; Mölter, A.; Mosler, G.; Madsen, C.; Nieuwenhuijsen, M.; Phuleria, H.; Pedeli, X.; Raaschou-Nielsen, O.; Ranzi, A.; Stephanou, E.; Sugiri, D.; Stempfelet, M.; Tsai, M. Y.; Lanki, T.; Udvardy, O.; Varró, M. J.; Wolf, K.; Weinmayr, G.; Yli-Tuomi, T.; Hoek, G.; Brunekreef, B. Evaluation of Land Use Regression Models for NO2 and Particulate Matter in 20 European Study Areas: The ESCAPE Project. Environ. Sci. Technol. 2013, 47, 4357-4364.

(29) Kerckhoffs, J.; Wang, M.; Meliefste, K.; Malmqvist, E.; Fischer, P.; Janssen, N. A. H.; Beelen, R.; Hoek, G. A National Fine Spatial Scale Land-Use Regression Model for Ozone. Environ. Res. 2015, 140, 440-448.

(30) Hoek, G.; Eeftens, M.; Beelen, R.; Fischer, P.; Brunekreef, B.; Boersma, K. F.; Veefkind, P. Satellite NO2 Data Improve National Land Use Regression Models for Ambient NO2 in a Small Densely Populated Country. Atmos. Environ. 2015, 105, 173-180.
(31) Schmitz, O.; Beelen, R.; Strak, M.; Hoek, G.; Soenario, I.; Brunekreef, B.; Vaartjes, I.; Dijst, M. J.; Grobbee, D. E.; Karssenberg, D. Data Descriptor: High Resolution Annual Average Air Pollution Concentration Maps for the Netherlands. Sci. Data 2019, 6, No. 190035.

(32) Junkermann, W.; Hacker, J. M. Ultrafine Particles in the Lower Troposphere Major Sources, Invisible Plumes, and Meteorological Transport Processes. Bull. Am. Meteorol. Soc. 2018, 99, 2587-2602.

(33) Moran, M. D.; Dastoor, A.; Morneau, G. Long-Range Transport of Air Pollutants and Regional and Global Air Quality Modelling. In Air Quality Management; Springer: Dordrecht, Netherlands, 2014; pp 69-98.

(34) Keuken, M. P.; Moerman, M.; Zandveld, P.; Henzing, J. S.; Hoek, G. Total and Size-Resolved Particle Number and Black Carbon Concentrations in Urban Areas near Schiphol Airport (the Netherlands). Atmos. Environ. 2015, 104, 132-142.

(35) Keuken, M. P.; Moerman, M.; Zandveld, P.; Henzing, J. S. Total and Size-Resolved Particle Number and Black Carbon Concentrations near an Industrial Area. Atmos. Environ. 2015, 122, 196-205.

(36) Hudda, N.; Gould, T.; Hartin, K.; Larson, T. V.; Fruin, S. A. Emissions from an International Airport Increase Particle Number Concentrations 4-Fold at $10 \mathrm{Km}$ Downwind. Environ. Sci. Technol. 2014, 48, 6628-6635.

(37) Shairsingh, K. K.; Jeong, C. H.; Wang, J. M.; Brook, J. R.; Evans, G. J. Urban Land Use Regression Models: Can Temporal Deconvolution of Traffic Pollution Measurements Extend the Urban LUR to Suburban Areas? Atmos. Environ. 2019, 196, 143-151.

(38) Morawska, L.; Ristovski, Z.; Jayaratne, E. R.; Keogh, D. U.; Ling, X. Ambient Nano and Ultrafine Particles from Motor Vehicle Emissions: Characteristics, Ambient Processing and Implications on Human Exposure. Atmos. Environ. 2008, 8113-8138.

(39) Kerckhoffs, J.; Hoek, G.; Vermeulen, R. A Nationwide Land Use Regression Model for Ultrafine Particles. Environ. Epidemiol. 2019, 3, 195 .

(40) Liu, J.; Li, W.; Wu, J.; Liu, Y. Visualizing the Intercity Correlation of PM2.5time Series in the Beijing-Tianjin-Hebei Region Using Ground-Based Air Quality Monitoring Data. PLoS One 2018, 13, $1-14$. 